\title{
Advantage for Emotional Words in Immediate and Delayed Memory Tasks: Could it be Explained in Terms of Processing Capacity?
}

\author{
Pilar Ferré \\ Rovira i Virgili University
}

\begin{abstract}
Emotional stimuli are better remembered and recognized than neutral ones. This advantage for emotional stimuli has been repeatedly obtained when testing long-term retention. However, there are contradictory results concerning retention of emotional information when short retention intervals are used. The aim of the present study was, on the one hand, to test the effect of retention interval on memory for emotional stimuli (Experiment 1). The results showed that cmotional information is better remembered than neutral information in both immediate and delayed memory tests, suggesting that the advantage for emotional information is not limited to long retention intervals. On the other hand, I tried to test the proposals made by Christianson and Nilsson (1984) and Bower (1992). These authors suggested that the advantage for emotional stimuli could be explained as emotional stimuli spending more processing capacity during acquisition, thus rendering less capacity available to encode simultaneously presented information (Experiments 2 and 3). Results showed that concurrent presentation of emotional stimuli did not inhibit the recall of neutral stimuli. These findings do not seem to support the proposals of Christianson and Nilsson (1984) and Bower (1992). According to these results, some mechanisms other than a greater spending of processing capacity have to be involved in the advantage for emotional information in memory.

Key words: affect-valenced words, processing capacity, emotional effect on memory, immediate retention
\end{abstract}

\begin{abstract}
Los estimulos emocionales se reconocen y recuerdan mejor que los neutros. La superior retención de los estímulos emocionales se ha obtenido, repetidamente, cuando se ha evaluado su retención a largo plazo. No obstante, los datos son contradictorios acerca de la obtención de este efecto cuando se usan intervalos de retención cortos. El objetivo del presente trabajo fue, por una parte, investigar el efecto del intervalo de retención sobre el recuerdo de los estímulos emocionales (Experimento 1). Los resultados mostraron que la información emocional se recuerda mejor que la neutra, tanto en las pruebas de retención inmediata como demorada, lo cual sugiere que la superioridad de la información emocional no se limita a los intervalos de retención largos. Por otra parte, se intentó poner a prueba la propuesta de Christianson y Nilsson (1984) y de Bower (1992), quienes sugirieron que los estímulos emocionales se recuerdan mejor porque centrarian la atención del sujeto durante la adquisición, dejando menos capacidad libre para procesar el resto de estímulos presentes (Experimentos 2 y 3 ). LOS RESULTADOS MOSTRARON QUE LA PRESENTACIÓN CONCURRENTE DE ESTIMULOS EMOCIONALES NO INHIBIÓ EL RECUERDO DE LOS ESTIMULLOS NEUTRALES. ESTOS HALLAZGOS no parecen apoyar la propuesta de Christianson y Nilsson (1984) y Bower (1992), sino que sugieren que deben existir otros mecanismos, distintos de la utifización de una mayor capacidad de procesamiento, que expliquen la superioridad de la información emocional en la retención. Palabras clave: palabras con valencia afectiva, capacidad de procesamiento, efecto emocional en la memoria, retención inmediata
\end{abstract}

Correspondence conceming this article should be addressed to Pilar Ferré, Departamento de Psicología. Universidad Rovira i Virgili. Carretera de Valts, s.n. 43007 Tarragona (Spain). E-mail: pfr@fcep.urves 
Memory for emotional events and emotional stimuli has been repeatedly shown to be enhanced relative to neutral ones. In laboratory studies, the superiority of emotional material on retention has been evidenced by using different types of emotional stimuli. For example, it has been shown that emotionally arousing pictures are better recalled and recognized than neutral ones (Bradley, Greenwald, Petry, \& Lang, 1992; Hamann, Cahill, \& Squire, 1997; Hamann, Monarch, \& Goldstein, 2000). Furthermore, some studies have shown that central details of slides containing emotional information are better remembered than those of slides containing neutral material (Burke, Heuer, \& Reisberg, 1992; Christianson \& Loftus, 1991; Christianson, Loftus, Hoffman, \& Loftus, 1991; Heuer \& Reisberg, 1990). In addition, memory for emotional information has also been tested by using words with an affective valence. With them, it has usually been found that emotionally valenced words are better remembered than non-emotional ones (Dewhurst \& Parry, 2000; Kleinsmith \& Kaplan, 1963; Parkin, Lewinsohn, \& Folkard, 1982; Phelps, LaBar, \& Spencer, 1997; Rubin \& Friendly, 1986). When looking at the above pattern of results, it seems clear that, in many laboratory studies, emotional stimuli show an advantage on retention over neutral ones (for reviews, see also Christianson, 1992a, 1992b; Christianson \& Safer, 1996; Revelle \& Loftus, 1992). From now on, I shall refer to this phenomenon as the "emotional effect on memory."

Retention interval was proposed to modulate the emotional effect on memory. By using affectively valenced words, some studies showed that high stimulus emotionality favors long- (Clark, Milberg, \& Ross, 1983; Kleinsmith \& Kaplan, 1963; Walker \& Tarte, 1963) but not short-term retention (Kleinsmith \& Kaplan, 1963, 1964; Walker \& Tarte, 1963). The same pattern of results was obtained by using slides (Christianson, 1984). Some authors interpreted these results in relation to Walker's (1958) action decrement theory, which suggests that new memory traces are initially inhibited to protect them from interference during consolidation. According to Kleinsmith and Kaplan $(1963,1964)$, such an inhibition would be greater with emotional stimuli, thus rendering short-term retention less probable for emotional words but heightening their retention after a delay. However, there is no convincing evidence for Kleinsmith and Kaplan's proposal (Baddeley, 1997; Eysenck, 1976).

Although the above results initially led to the proposal that the emotional effect on memory would only be observed when testing long-term retention, contradictory results have subsequently been obtained. They suggest that the differential effect of emotional material on memory, depending on the retention interval, is far from clear. First of all, Christianson and Lofus (1987) found that arousal impairs memory for detail in both immediate and delayed tests. Secondly, Kebeck and Lohaus (1986) failed to obtain any emotionality effect on memory either in an immediate or in a delayed test. Third, several authors found that even when using short retention intervals there was a higher retention of emotional stimuli (Burke et al., 1992; Christianson et al., 1991; Ellis, Detterman, Runcie, McCarver, \& Craig, 1971; Wessel, Van der Kooy, \& Mercklebach, 2000). On the other hand, although as mentioned, there are some studies testing short-term retention of emotional stimuli, their immediate retention has seldom been tested, as studies testing short-term retention have commonly used retention intervals of several minutes (Eysenck, 1976). In the literature reviewed (e.g., Revelle \& Loftus, 1992), I was able to find only three early studies that tested immediate retention of emotional information (Corteen, 1969; Kaplan, Kaplan, \& Sampson, 1968; Maltzman, Kantor, \& Langdon, 1966). Two of them obtained an enhancing effect of stimulus emotionality on recall (Corteen, 1969; Maltzman et al, 1966) whereas the other one reported a higher retention for neutral over emotional stimuli (Kaplan et al., 1968). Therefore, it has yet to be established whether the advantage for emotional information can be consistently observed in immediate memory tests.

Concerning the mechanisms of the emotional effect on memory, several factors have been hypothesized. Some factors are related to early perceptual processing (factors related to arousal, distinctiveness or unusualness of the event, and attentional or preattentive factors), whereas others are related to a late conceptual processing (poststimulus elaboration; for reviews, see Christianson, 1992a, 1992b; Reisberg \& Heuer, 1993, 1995). Particularly, Christianson (1992a, 1992b) proposed that the initial stages of processing emotional information could involve preattentive processing, whereas the later stages would involve controlled processing. According to this proposal, emotional stimuli would be better remembered either because they are preattentively or automatically processed or because they receive more elaboration in the later stages of processing. Christianson (1992a, 1992b) also suggested that both mechanisms were not necessarily exclusive, and both could be involved in the advantage of emotional material on memory.

Christianson (1992a, 1992b) proposed an additional mechanism, related to attention, that could act at an early perceptual processing stage. This hypothetical attentional mechanism could explain the finding that retention of central events is usually better and, memory for peripheral details worse, in emotional slides respective to neutral ones (Burke et al., 1992; Christianson, 1984; Christianson \& Loftus, 1987, 1991). This effect could well be explained as emotional events capturing individuals' attention. Therefore, when confronted with an emotional scene, participants would spend more time looking at the central details of the event (which contain the emotional information) and less time looking at the periphery (Christianson et al., 1991). However, although it initially seemed a promising 
explanation, such improvement on recall of central details at the expense of memory for peripheral information has not always been found. For example, Heuer and Reisberg (1990) and Libkuman, Nichols-Whitehead, Griffith, and Thomas (1999) have shown that both central and peripheral details of emotional information are better remembered than their corresponding counterparts in neutral stimuli. Moreover, Wessel et al. (2000) have shown that the differences between recall of central and peripheral information in emotional stimuli is not a robust phenomenon. Instead, it seems to be clearly dependent on the experimental circumstances. This questioning of the central/peripheral distinction clearly represents a challenge to the attentional capacity proposal.

Furthermore, Christianson et al. (1991) conducted several experiments in order to assess directly the interpretation based on an attentional mechanism. They used the number of eye fixations as a measure of attention and concluded that attention, at least when using this measure, could not fully explain why people retain certain details better from emotional than from neutral events. Similarly, Wessel et al. (2000) observed that, although participants spend more time looking at central details of emotional slides, this pattern is not always accompanied by better retention of these central details. This latter result clearly shows that a differential location of attention at the time of stimulus processing does not imply a differential recall pattern of central and peripheral details.

Lastly, Christianson and Nilsson (1984) proposed another way of measuring attention. They based their proposal on a conception of attentional capacity as a limited resource. In this sense, high levels of arousal (due, for example, to processing highly emotional stimuli) would spend a great amount of attentional capacity, thus rendering less capacity available to encode simultaneously presented information. Thus, better memory for central details of emotional events and worse memory for their peripheral aspects would be explained by an impoverished attentional capacity for the latter, at the moment of encoding. In support of their proposal, Christianson and Nilsson (1984) showed that words presented together with slides of facial injuries are remembered and recognized worse than words accompanying neutral faces. The same line of reasoning was sustained by Bower (1992). This author hypothesized that emotional information would receive higher priority in processing and would persist longer in working memory. This would result in a greater processing of these items and less processing of the accompanying stimuli, either because they do not enter working memory or they do not receive the same amount of rehearsal, because working memory has been taken up by the emotional item. Thus, according to both Christianson and Nilsson (1984) and Bower (1992) it seems that the emotional effect on memory could be explained, at least partially, by a high priority in processing emotional information, which would result in an impairment of the processing of simultaneously presented stimuli. Although these proposals were made some years ago, I could not find any study directly addressing them, aside from the Christianson and Nilsson's (1984) work and the previously reported studies testing memory for central and peripheral details of slides (Burke et al., 1992; Christianson et al., 1991; Heuer \& Reisberg, 1990; Libkuman et al., 1999; Wessel et al., 2000). However, these studies are difficult to compare and interpret because of the variability in the definitions of central and peripheral information. In addition, some studies obtained conclusions that would provide support to a mechanism similar to that proposed here (Ellis et al., 1971), whereas other studies do not (Contini \& Whissell, 1992; Howard-Voyer \& Whissell, 1994). But the purpose of these studies was not to test such a mechanism. Furthermore, thete are no studies using words as stimuli directly addressing Bower's (1992) and Christianson and Nilsson's (1984) proposals.

The aim of the present study is twofold. On the one hand, and given the contradictory results mentioned in this introduction, I was interested in further investigating the influence of retention interval on the emotional effect on memory. On the other hand, a second purpose was to investigate the mechanism responsible for the emotional effect on memory. Specifically, I have tested Christianson and Nilsson's (1984) proposal concerning emotional stimuli spending more processing capacity than neutral ones and, as a result, rendering less capacity avaitable to encode other simultaneously presented information. In order to achieve this goal, I focused on testing immediate memory because, according to Bower (1992), this is the stage at which emotional information would receive higher processing priority.

\section{Experiment 1}

Results from several studies initially showed that memory for emotional stimuli was poorer than for neutral ones when tested shortly after the acquisition phase (Christianson, 1984; Kleinsmith \& Kaplan, 1963, 1964; Walker \& Tarte, 1963) whereas, when tested after some delay, retention seemed to be better for emotional information (Christianson, 1984; Clark et al., 1983; Kleinsmith \& Kaplan, 1963; Walker \& Tarte, 1963). Although that was considered a consistent effect, more recent results have evidenced that the effect of the retention interval on memory for emotional stimuli fails to be clear (Burke et al., 1992; Christianson \& Loftus, 1987; Christianson et al., 1991; Kebeck \& Lohaus, 1986; Wessel et al., 2000). Furthermore, immediate memory tasks have seldom been used to test the emotional effect on memory and, when used, a consistent pattern of results has not been reported (Corteen, 1969; Kaplan et al., 1968; Maltzman et al., 1966). Given these contradictory findings, the aim of the first experiment was to test memory for emotional and neutral words by using immediate and delayed tests. 


\section{Method}

\section{Participantts}

Twenty-one undergraduate students $(1$ male and 20 females, aged between 19 and 24) participated in this experiment as a course requirement.

\section{Material}

The stimuli used were 40 words (20 emotional and 20 neutral words; see the Appendix), obtained from a normative study performed by Algarabel (1996), in which 2000 participants had rated a set of 1917 Spanish words according to several variables. Words' pleasantness had been rated with a score ranging from 1 to 7 . Emotional words were chosen from among those with the most extreme scores (values ranging from 5.5 to 7 for pleasant words and ranging from 1 to 2 for unpleasant words), whereas neutral words were chosen from among those with a score ranging from 3 to 4. Neutral and emotional words were matched as closely as possible in length, frequency, and concreteness. Student's $t$-tests showed that there were no significant differences for length, concreteness, or frequency between the two sets of words (all $t s<0.9$ ).

Eight 5-word trials were constructed with these 40 words. Four trials were made up of 3 emotional plus 2 neutral words. The remaining four trials included 2 emotional and 3 neutral words. The order of the words in any given trial and the order of trials were randomized, so that four different orders were created to which participants were assigned.

The equipment included an IBM-compatible computer, with a color monitor. The Superlab Program for Windows (Abboud \& Sugar, 1990) was used to control stimuli presentation.

\section{Procedure}

Participants were informed that they were taking part in a memory study. They were told that, in any given trial, they would see a set of words appearing on the screen and that they should try to remember as many of them as possible, regardless of their presentation order.

The sequence in each trial was as follows: A warning signal (the word ready?) appeared on the screen. Participants were free to press any key to self-administer the trial. When doing so, the sequence of five words was presented. Before every word, a cross-fixation point ( $250 \mathrm{~ms}$ ) appeared at the same place as the stimulus to be presented. Then, a word was presented, remaining one second in the center of the screen. The interval between words was $250 \mathrm{~ms}$. Immediately after the end of each trial, participants had to write down all the words they could remember on a sheet of paper. Participants self-administered the trials by pressing any key on the keyboard. There were two practice trials and eight experimental trials. After having performed the eight trials, participants were told that the experiment was finished and requested to come back in 15 minutes for a second experiment. This instruction was meant to discourage participants from thinking about the words seen during the experimental session. When they returned, they were requested to write down all the words they could remember from the previous phase. They were given 5 minutes to complete the task.

\section{Results}

The overall number of emotional and neutral words recalled both immediately and after the 15-minute delay was computed (see Table 1). Recall of emotional and neutral words was compared by a repeated measures ANOVA. The within-subject factors were emotionality (emotional and neutral words) and delay (immediate and delayed testing). The ANOVA showed a main effect of both emotionality, $F(1,20)=10.6, p<.01$, and delay, $F(1,20)=505.1, p<$ .005 . The analysis failed to show a significant interaction effect, $F(1,20)=0.18, p=68$. $T$-Tests were carried out to compare retention of emotional and neutral words in immediate and delayed testing, separately. A significant difference between the recall of emotional and neutral words was observed both in the immediate and delayed testing conditions, $t(20)=2.5, p<.05$, and $t(20)=2.9, p<.01$, respectively.

The above results suggest that emotional information is better remembered than neutral material when tested with a delay between acquisition and retention. These results are in agreement with previous work reporting the emotional effect on memory when tested after a retention interval (Christianson, 1984, 1992a, 1992b; Clark et al., 1983;

Table 1

Means and Standard Error of Measurements of the Number of Emotional and Neutral Words Recalled in Immediate and Delayed Tests in Experiment I

\begin{tabular}{lcc}
\hline Type of word & Immediate test & Delayed test \\
& $M \pm S E M$ & $S E M$ \\
\hline Neutral words & $13.7 \pm 0.5$ & $3.8 \pm 0.4$ \\
Emotional words & $15.3 \pm 0.5$ & $5.1 \pm 0.4$ \\
\hline
\end{tabular}


Kleinsmith \& Kaplan, 1963; Revelle \& Loftus, 1992; Walker \& Tarte, 1963). More interesting, the present results also show that emotional words are better remembered than neutral ones when an immediate test is performed. In this sense, these results coincide with some experimental work that has found the emotional effect on memory with short retention intervals (Burke et al., 1992; Christianson ct al., 1991; Corteen, 1969; Ellis et al., 1971; Maltzman et al., 1966; Wessel et al., 2000). Furthermore, this experiment adds to the previous literature the finding of having encountered the emotional effect on memory by testing immediate memory, a paradigm that has seldom been used in this field. Therefore, the present results suggest that the emotional effect is not restricted to long retention intervals and, in this sense, they are not in accordance with Kleinsmith and Kaplan's (1963, 1964) suggestion concerning Walker's (1958) action decrement theory. On the other hand, the obtention of the emotional effect immediately after stimulus presentation makes it reasonable to speculate about some mechanism related to processing capacity to explain the effect. Experiment 2 explores such a possibility.

\section{Experiment 2}

Given that results from Experiment 1 suggest that the emotional effect can be obtained in immediate memory tests, the aim of Experiment 2 was to test whether the mechanism involved in this effect may be related to attentional capacity. Christianson and Nilsson (1984) and Bower (1992) hypothesized that emotional stimuli would spend a greater amount of processing capacity than neutral ones, thus rendering less capacity available to encode simultaneously presented information. My prediction was that, if the effect of the emotional content of words on memory is due to emotionally valenced words spending more processing capacity, then the inclusion of such words in a to-beremembered set of stimuli would result in a detrimental effect on recall of the remaining words presented in that set. Conversely, if emotional words do not spend more processing capacity than neutral information, memory for a set of words should be the same regardless of whether they are put together in a given to-be-remembered trial with emotional or with neutral stimuli.

\section{Method}

\section{Participants}

Twenty-two undergraduate students (4 males and 18 females aged between 19 and 33), different from those in Experiment 1, participated in this experiment to fulfill a course requirement.

\section{Material}

The stimuli used were 50 words (12 emotional words and 38 neutral words; see the Appendix) obtained from the same pool and using the same criterion as in Experiment 1 (Algarabel, 1996). Emotional and neutral words were matched as closely as possible in length, frequency, and concrcteness. There were no significant differences either for length, frequency, or concreteness between the two sets of words (all $t s<1.5$ ).

Ten 5-word trials were constructed with these 50 words. There were four trials made up of only 5 neutral words (neutral trials) and six trials containing 3 neutral words plus 2 emotionally valenced words (emotional trials). Neutral trials were matched as well as possible with emotional trials. Mann-Whitney tests were performed to ensure that there were no differences in length, frequency, or concreteness between words included in emotional and neutral trials (all $p s>.25$ ). The dependent variable was the total amount of neutral words recalled outside the positions occupied by emotional words in emotional trials and by their matched neutral words in neutral trials. Therefore, an additional Mann-Whitney analysis was conducted to make sure that these 3 neutral words were well matched in emotional and neutral trials in length, concreteness, and frequency (all $p \mathrm{~s}$ $>$.13). The order of the words in any given trial and the order of trials were randomized, creating four different orders to which participants were assigned. In addition to the ten experimental trials, there were two practice trials, made up of 5 neutral words each. The equipment and software were the same as in Experiment 1.

\section{Procedure}

Participants were informed that they were taking part in a memory study. They were told that, in a given trial, they would see a set of words appearing on the screen and that they should try to remember as many words as possible.

The sequence in each trial was as follows: A warning signal (the word ready?) appeared on the screen. Participants were free to press any key to self-administer the trial. When doing so, the 5 words contained in a given trial appeared simultaneously on the screen, in a column. They remained on the screen for 2 seconds. Immediately after the end of each trial, participants had to write down all the words they could remember. In order to see the next trial, participants had to press any key on the keyboard.

The dependent variable was the total amount of neutral words recalled. In emotional trials, only data corresponding to those in which participants actually remembered the emotional words contained in them were considered. In neutral trials, dala were also collected only for those trials in which the neutral words occupying the same positions as the emotional words in their matched emotional trials were correctly recalied. In emotional trials, the dependent variable 
was obtained by counting the number of neutral words recalled from the three words that were included in any trial. In neutral trials, the dependent variable was obtained by counting the number of neutral words recalled from those that occupied the same positions as neutral words in their matched emotional trials. Therefore, the maximum number of neutral words recalled in any emotional or neutral trial could be 3 .

\section{Results}

Results are shown in Table 2. The average performance on emotional and neutral trials was compared by a $t$-test. This analysis failed to show any significant difference between the two types of trials in the number of neutral words recalled, $t(21)=0.44, p=.66$. In order to determine whether emotional words were actually better recalled than neutral ones, a $t$-test was conducted on the proportion of emotional and neutral words remembered in the overall experiment (computed by taking into account the total amount of emotional and neutral experimental words presented, respectively). The analysis revealed a significant difference between the proportion of emotional $(M \pm S E M=$ $0.75 \pm 0.02)$ and neutral $(M \pm S E M=0.67 \pm 0.03)$ words recalled, $t(21)=3.1, p<.01$.

These results suggest that, although better remembered than neutral ones, emotional words did not seem to disrupt the encoding of simultaneously presented information. Therefore, the present results did not support the proposal of Christianson and Nilsson (1984) and Bower (1992) in regard to emotional stimuli spending greater processing capacity than neutral ones, at least when using words as stimuli. In an attempt to explain this null finding, it was speculated that perhaps the task employed in Experiment 2 did not create a real competition for processing capacity of emotionally valenced words with neutral words. In this sense, it could be that two seconds was long enough to comfortably process the overall set of stimuli. Therefore, some task involving more competition between stimuli could be required to determine whether emotional stimuli spend greater processing capacity than neutral ones. Experiment 3 was conducted to test that possibility.

\section{Experiment 3}

The aim of this experiment was to further explore, by a different experimental procedure, whether the mechanism responsible for the higher recall of emotional words is that they spend more processing capacity than neutral ones. For this purpose, the situation was made more demanding for the participants, requiring them to perform two tasks simultaneously, to see whether, under these conditions, there is real competition between materials and, as a result, emotional information becomes the center of attentional resources. Therefore, a task was used in which participants had to learn sets of numbers and concurrently rate emotionally valenced and neutral words according to their emotionality. It was hypothesized that, if processing of emotional words spends greater capacity than processing of neutral ones, poorer retention should be observed of numbers in trials where emotional words and numbers are presented concurrently, as compared with trials in which neutral words are simultaneously presented with numbers.

\section{Method}

\section{Participants}

Twenty undergraduate students ( 2 males and 18 females aged between 19 and 21), different from those in Experiments 1 and 2, participated in this experiment in order to fulfill a course requirement.

\section{Material}

The words used in the present experiment were the same as those used in Experiment 2 (see the Appendix). Additionally, a set of 50 two-digit numbers was selected to be presented as the to-be-remembered items. Any two-digit number appeared only once in the overall experimental session. The stimuli were arranged in ten trials as follows: Four trials (neutrai trials) consisted of a set of 5 numbers plus a set of 5 neutral words, arranged in five number-word

Tabile 2

Mean Number of Neutral Words Recalled in Neutral and Emotional Trials in Experiment 2 and Total Amount of 2-Digit Numbers Correctly Recalled in Neutral and Emotional Trials in Experiment 3

\begin{tabular}{|c|c|c|}
\hline Experiment & & $M \pm S E M$ \\
\hline \multicolumn{3}{|c|}{ Experiment 2} \\
\hline & Neutral words recalled in neutral trials & $1.89 \pm 0.13$ \\
\hline & Neutral words recalled in emotional trials & $1.85 \pm 0.13$ \\
\hline \multicolumn{3}{|c|}{ Experiment 3} \\
\hline & Two-digit numbers recalled in neutral trials & $2.47 \pm 0.12$ \\
\hline & Two-digit numbers recalled in emotional trials & $2,60 \pm 0.18$ \\
\hline
\end{tabular}


pairs. The remaining six trials (emotional trials) consisted of a set of 5 numbers plus a set of 2 emotional and 3 neutral words, arranged in five number-word pairs. The two types of trials were matched in the number of syllables of the Spanish names of the to-be-remembered numbers. The order of the words in any given trial and the order of the ten trials were randomized, creating four different orders to which participants were assigned. The equipment and software used were the same as in Experiments 1 and 2.

\section{Procedure}

Participants were informed that they were taking part in a memory study in which their ability to perform two simultaneous tasks would also be investigated. They were told that they would see sets of numbers appearing together with words in the center of the screen. They were instructed to try to remember as many numbers as possible and, simultaneously, to rate the words' emotionality by writing a value ranging from 1 to $5(1=$ neutral and $5=$ very emotional). Participants were not informed about the differences in the emotional content of the words. They were encouraged to perform both tasks as well as possible, because both of them were important for the experimental purposes.

Each trial was as follows: A warning signal (the word ready?) appeared on the screen. Participants were free to press any key in order to self-administer the trial. When they did so, the sequence of five number-word pairs was presented. Before each pair, the symbol $X X X X X$ appeared in the center of the screen and remained there for 3 seconds. After that, the number-word pair appeared and remained at the center of the screen for 1 second. After each pair, the symbol $X X X X X$ was presented for 3 seconds, during which, participants had to perform their ratings. Immediately after the end of a given trial, participants were instructed to write down as many numbers as they could remember, regardless of their order of appearance. Participants self-administered the trials by pressing any key in the keyboard. The dependent variable was the total amount of numbers remembered in a given trial and its maximum value was five.

Participants performed two practice and ten experimental trials. After finishing, the experimenter talked with them about memory experiments. After 3 minutes, a surprise memory test was administered and participants were asked to write down as many words as they could remember from those previously presented. They were given 5 minutes to perform this task.

\section{Results}

Results are shown in Table 2. The amount of two-digit numbers recalled as a function of the type of trial was analyzed by Student's $t$-test that failed to show any significant difference between the amount of numbers remembered in emotional and neutral trials, $t(19)=0.74, p$ $=.47$. In order to determine whether emotional words actually were better remembered than neutral ones, the proportion of emotional and neutral words recalled (taking into account the total number of emotional and neutral words presented) in the delayed memory test was also analyzed. In this case, a $t$-test revealed a significant difference in the proportion of emotional $(M \pm S E M=0.27 \pm 0.04$ ) and neutral $(M \pm S E M=0.09 \pm 0.01)$ words recalled, $t(19)=$ $5.06, p<.001$.

The above results suggest that, regardless of the emotional content of the words presented in the concurrent task, participants' recall of the two-digit numbers was not different in emotional and neutral trials. This is true despite the fact that, when tested after a 3-minute period, participants remembered a greater proportion of emotional versus neutral words. Therefore, the present results suggest that the greater retention of emotional over neutral words does not seem to be due to a disruption of the encoding of simultaneously presented information. In this sense, the present results also fail to confirm the prediction that emotional words would spend greater processing capacity than neutral ones (Bower, 1992; Christianson \& Nilsson, 1984).

\section{Discussion}

The aim of the present study was twofold. The first goal was to investigate the influence of retention interval on the emotional effect on memory. A second purpose was to test whether the mechanism responsible for this higher retention of emotional information could be explained by emotional stimuli spending a greater amount of processing capacity than neutral ones, as proposed by Christianson and Nilsson (1984) and Bower (1992).

Concerning the first goal, results from Experiment 1 show that emotionally valenced words are better remembered than neutral ones when tested both immediately and after a 15- minute delay. The higher retention of emotional stimuli obtained in an immediate memory test is the most relevant finding of Experiment 1, as studies testing the emotional effect on memory have commonly used long-term retention intervals, ranging from minutes to hours and even days (see Revelle \& Loftus, 1992, for a review). The present results suggest that this effect is not restricted to such long retention intervals. Hence, they are in accordance with previous findings reporting higher retention of emotional stimuli over neutral ones with short retention intervals-usually several minutes (Burke et al., 1992; Christianson et al., 1991; Ellis et al., 1971; Wessel et al., 2000; see also Eysenck, 1976, for a review) - and with some studies using immediate memory tests (Corteen, 1969; Malizman et al., 1966). In addition, results from Experiment 1 clearly suggest that Walker's (1958) action decrement theory cannot explain the emotional effect on memory, as emotionally charged words 
are better retained than their non-emotional counterparts immediately after being presented.

An additional finding of Experiment 1 deserving some comment is the lack of interaction between the type of stimulus and delay. This suggests that the magnitude of the advantage for emotional words on memory is the same in the immediate and in the delayed test. If neutral words were more quickly forgotten than emotional ones, such an interaction should have been obtained. This finding is relevant because it indicates that there is no differential pattern of forgetting between emotional and neutral words. As repeatedly stated in this paper, most of the previous work consistently reporting the emotional effect on memory has relied on long retention intervals. That is, the advantage for emotional stimuli on retention over neutral stimuli in those studies may have been due to their differential pattern of forgetting. The present results contribute to ruling out this possibility.

The emotional effect on retention obtained in the immediate test in Experiment 1 could be compatible with an explanation in terms of attentional processes, as the emotional effect on memory is observed immediately after having seen the words. Bower (1992) and Christianson and Nilsson (1984) proposed such a mechanism, relating it to the spending of processing capacity. According to this proposal, it was predicted that if emotional stimuli receive higher processing priority, stimuli presented together with them would have less processing capacity available than if they had been presented together with neutral information. This prediction was tested by comparing the amount of neutral words remembered in trials that contained emotional words with matched trials not including emotional stimuli (Experiment 2). Results from this experiment did not confirm the prediction. No significant effect was found on the recall of the remaining items when including 2 emotional words in a given set. This null effect cannot be explained as a result of an unfortunate selection of the emotional stimuli, since when analyzing the proportion of emotional and neutral words remembered, the usual advantage for emotionally valenced words appears.

An alternative explanation is that the task was too easy and that words did not actually have to compete for capacity resources. That did not seem a convincing explanation, because the majority of participants were not able to remember the five words in any given trial (see Table 2). However, in order to discard this explanation in terms of a low difficulty of the task, Experiment 3 was conducted with the aim of presenting participants with a more demanding situation, in which they had to perform two tasks simultaneously. Results from Experiment 3 clearly show that the amount of two-digit numbers remembered in a given trial was the same regardless of whether they were presented concurrently with emotional or with neutral words. Therefore, these results point in the same direction as those of Experiment 2. Once again, the fact that the proportion of emotional words remembered in a surprise memory test was higher than that of neutral words rules out the possibility of an inadequate selection of the materials. In addition, the fact that participants, on the average, were far from remembering the 5 numbers (see Table 2) precludes an interpretation in terms of the task being too easy and therefore not involving a great capacity demand.

The null findings obtained in Experiments 2 and 3 could be regarded as contradictory to the studies that have obtained a differential pattern of recall between central and peripheral details of emotional and neutral slides (Burke et al., 1992; Christianson \& Loftus, 1991; Christianson et al., 1991), which Christianson (1992a, 1992b) cites in support for the attentional hypothesis. However, as stated in the introduction, this differential recall pattern has not always been observed (Heuer \& Reisberg, 1990; Libkuman et al., 1999; Wessel et al., 2000). Furhermore, the relationship between attentional processes and central/peripheral recall is far from being established (Christianson et al., 1991; Wessel et al., 2000).

As mentioned, there is an additional early study that, to a certain extent, assessed the processing capacity spent by emotional versus neutral items. Ellis et al. (1971), using sets of pictures of familiar objects as neutral stimuli, showed that in trials where an emotional photograph was included, there was poor retention of the items that immediately preceded and followed it. Although these results can be interpreted as emotional stimuli spending greater processing capacity, this interpretation may not be the most suitable one. There may be more differences other than the emotional valence between neutral and emotional stimuli in that study, as the former were line drawings whereas the emotional items were black and white photographs. In this sense, it could well be that the higher retention of the emotional photographs was due to their greater distinctiveness, rather than to their higher emotionality. In fact, there is much experimental evidence supporting that recall is enhanced by items that are distinctive, such as low frequency (Dewhurst, Hitch, \& Barry, 1998) or high imageable words (Dewhurst \& Conway, 1994).

On the other hand, the majority of the above reviewed studies were performed with images as stimuli. There are, however, two studies using verbal stimuli that obtained findings relevant to the present experiments, although their goal was not related to testing Bower's (1992) and Christianson and Nilsson's (1984) proposals. Contini and Whissell (1992) and Howard-Voyer and Whissell (1994) tested the immediate retention of nonsense syllables associated either with neutral or with emotional words. They observed that there is no significant difference in recall of nonsense syllables regardless of whether they are encoded together with neutral or with emotional words. In this sense, the present results are clearly in accordance with these two studies in showing a lack of effect on the recall of the stimuli of the emotional content of information presented simultaneously with the stimuli. 
Which, then, are the mechanism/s involved in the emotional effect on memory? Christianson also proposed that emotional stimuli might be processed in a preattentive way. He suggested that this preattentive processing would be fast, nonconscious, context independent, independent of processing resources, able to carry out parallel processing of different inputs, and effortless (Christianson, $1992 \mathrm{a}, 1992 \mathrm{~b})$. If this were the case, it would not be necessary to postulate a greater spending of processing capacity by emotional information because, on the contrary, a preattentive mechanism would involve higher facility in processing those stimuli. In fact, there is jncreasing evidence of such preattentive processing. For example, Öhman and Soares $(1993,1998)$ reported that emotional stimuli seem to be able to engage an automatic stimulusanalysis mechanism. Several studies have also shown that emotional stimuli can be processed with greater fluency (e.g., Hansen \& Hansen, 1988; Mathews, Pitcaithly, \& Mann, 1995). However, the relationship of this hypothetical preattentive mechanism with the emotional effect on memory remains to be established. Moreover, the fact that it is not necessary to process stimuli according to their emotional attributes to obtain higher retention for emotionally-valenced pictures or words over their neutral counterparts (Ferré a, b, in press) may indicate that these emotional properties could, in effect, be processed without deliberate intention.

To sum up, the contribution of the present study is to have clearly shown that emotionally valenced words are better remembered than neutral ones when tested both immediately after their presentation and after a delay, thus suggesting that the emotional effect on memory is not restricted to long retention intervals and that it does not seem to be due to a differential pattern of forgetting for emotional and neutral words. Furthermore, this is the first study, using verbal stimuli and an immediate retention task, that directly addresses Bower's (1992) and Christianson and Nilsson's (1984) proposals concerning emotional stimuli spending more processing capacity than neutral ones. Despite using two different experimental procedures, no findings supporting these proposals were obtained. Therefore, some mechanism other than a greater spending of processing capacity has to be involved in the advantage for emotional information in nemory.

\section{References}

Abboud, H., \& Sugar, D. (1990). Siperlab Pro. Experimenal Laboratory Software for Windows. Phoenix, AZ: Cedrus Corporation.

Algarabel, S. (1996). Indices de interés psicolinguístico de 1917 palabras castellanas. Cognitiva, 8, 43-88.

Baddeley, A.D. (1997). Human memory: Theory and practice. Hove, UK: Psychology Press.
Bradley, M.M, Greenwald, M.K., Petry, M.C., \& Lang, P.J. (1992). Remembering pictures: Pleasure and arousal in memory. Jounal of Experimental Psychology: Leaming, Memory and Cognition, 18, 379-390.

Bower. G.H. (1992). How might emotions affect learning? In Christianson, S.-A. (Ed.), The handbook of emotion and memory: Research and theory (pp. 3-31). Hillsdale, NJ: Erlbaum.

Burke, A., Heter, F., \& Reisberg, D. (1992). Remembering emotional events. Menory and Cognition, 20, 277-290.

Christianson, S.-A. (1984). The relationship between induced emotional arousal and amnesia. Scandinavian Journal of Psychology, 25, 147-160.

Christianson, S.-A. (1992a). Remembering emotional events. In S.-A. Christianson (Ed.), The handbook of enotion and memory: Research and theory (pp. 307-340). Hillsdale, NJ: Erlbaum

Christianson, S.-A. (1992b). Emotional stress and eyewitness menory: A critical review. Psychological Bulletin, /12, 284309.

Christianson, S.-A., \& Loftus, E.F. (1987). Memory for traumatic events. Applied Cognitive Psychology, I, 225-290.

Christianson, S.-A., \& Loftus, E.F. (1991). Remembering emotional information: The fate of detailed information. Cognition and Emotion, 5, 81-108.

Christianson, S.-A., Loftus, E.F., Hoffman, H., \& Loftus, G.R. (1991). Eye fixations and memory for emotional events. Jounal of Experimental Psychology: Leaming, Memory and Cognition, 17, 693-701.

Christianson, S.-A., \& Nilsson, L.G. (1984). Functional amnesia as induced by psychological trauma. Memory and Cognition, 12, 142-15.5.

Christianson, S.-A., \& Sufer, M.A: (1996). Emotional events and emotions in autobiographical memories. In D.C. Rubin (Ed.), Remenbering our past: Studies in autobiographical memory (pp. 218-243). Cambridge, UK: Cambridge University Press.

Clark, M.S., Milberg, S., \& Ross, J. (1983). Arousal cues arousalrelated material in memory: Implications for understanding effects of nood on memory. Joumal of Verbal Leaming and Verbal Behavior. 22, 633-649.

Contini, L., \& Whissell, C. (1992). Memory disadvantages for CVC associates of emotional words. Perceptual and Motor Skills, 75, 427-431.

Corteen, R.S. (1969). Skin conductance changes and word recall. British Jounal of Psychology, 60, 81-84.

Dewhurst. S.A., \& Conway, M.A. (1994). Picture, images, and recollective experience. Journal of Experimental Psychology: Learning, Memory and Cognition, 20, 1088-1098.

Dewhurst, S.A., Hitch, G.J., \& Barry, C. (1998). Separate effects of word frequency and age of acquisition in recognition and recall. Journal of Emotion and Recollective Experimental Psychology, 24, 284-298.

Dewhurst, S.A., \& Parry, L.A. (2000). Emotionality, distinctiveness, and recollective experience. European Journal of Cognitive Psychology, 12, 541-551. 
Ellis, N.R., Detterman, D.K., Runcie, D., McCarver, R.B., \& Craig, E.M. (1971). Amnesic effects in short-term memory. Joumal of Experimental Psychology, 89, 357-361.

Eysenck, M.A. (1976). Arousal, learning and memory. Psychological Bulletin, 83, 389-404.

Ferré, P. (in press-a). Effects of level of processing on memory for affectively valenced words. Cognition and Emotion.

Ferré, P. (in press-b). Recuerdo de imágenes emocionales y niveles de procesamiento. Psicothema.

Hamann, S.B., Cahill, L., \& Squire, L.R. (1997). Emotional perception and memory in amnesia Neuropsychology, 11, 104-113.

Hamann, S.B., Monarch, E.S., \& Goldstein, F.C. (2000). Memory entancement for emotional stimuli is impaired in early Alzheimer's Disease. Neuropsychology, 14, 82-92.

Hansen, C.H., \& Hansen, R.D. (1988). Finding the face in the crowd: An anger superiority effect. Journal of Personality and Social Psychology, 54, 917-924.

Heuer, F., \& Reisberg, D. (1990). Vivid memories of emotional events: The accuracy of remembered minutiae. Memory and Cognition, 18, 496-506.

Howard-Voyer, C., \& Whissell, C. (1994). Emotional descriptors of words as predictors of recall in a paired-associate task. Perceptual and Moror Skills, 78, 1187-1191.

Kaplan, R. Kaplan, S., \& Sampson, J.R. (1968). Encoding arousal factors in free recall of verbal and visual material. Psychonomic Science, 12, 73-74.

Kebeck, G., \& Lohaus, A. (1986). Effect of emotional arousal on free recall of complex material. Perceptual and Motor Skills. $63,461-462$.

Kleinsmith, L.J., \& Kaplan, S. (1963). Paired-associate learning as a function of arousal and interpolated interval. Journal of Experimental Psychology, 65, 190-193,

Kleinsmith, L.J., \& Kaplan, S. (1964). The interaction of arousal and recall interval in nonsense syllable paired-associate learning. Journal of Experimental Psychology, 67, 124-126.

Libkuman, T.M., Nichols-Whitehead, P., Griffith, J., \& Thomas, R. (1999). Source of arousal and memory for detail. Memtory and Cognition, 27, 166-190.

Maltzman, I., Kantor, W., \& Langdon, B. (1966). Immediate and delayed retention, arousal, and the orienting and defensive reflexes. Psychonomic Science, 6, 445-446.

Matthews, G., Pitcaithly, D., \& Mann, R.L.E. (1995). Mood, neuroticism and the encoding of affective words. Cognitive Therapy Research, 19, 563-587.
Öhman, A., \& Soares, J.J.F. (1993). On the automatic nature of phobic fear: Conditioned electrodermal responses to masked fear-relevant stimuli. Jourtal of Abnormal Psychology. 102, $121-132$.

Öhman, A., \& Soares, J.J.F. (1998). Emotional conditioning to masked stimuli: Expectancies for aversive outcomes following nonrecognized fear-relevant stimuli. Journal of Experimental Psychology: General, 127, 69-82.

Parkin, A.J., Lewinsohn, J., \& Folkard, S. (1982). The influence of emotion on immediate and delayed retention; Levinger and Clark reconsidered. British Journal of Psychology, 73, 389393.

Phelps, E.A., LaBar, K.S., \& Spencer, D.D. (1997). Memory for emotional words following unilateral temporal lobectomy. Brain and Cognition, 35, 85+109.

Reisberg, D., \& Heuer, F. (1993). Remembering the details of emotional events. In E. Winograd \& U. Neisser (Eds.), Affect and accuracy in recall: Studies of flashbulb memories. Emory Symposia in Cognition, 4 (pp. 162-190). New York: Cambridge University Press.

Reisberg, D., \& Heuer, F. (1995). Emotion's multiple effects on memory. In J.L. McGaugh, N.M. Weinberger, \& G. Lynch (Eds.), Brain and memory: Modulation and mediation of neuroplasticity (pp. 84-92), New York: Oxford University Press.

Revelle, W., \& Loftus, D. (1992). The implications of arousal effects for the study of affect and memory. In Christianson, S.-A. (Ed.), The handbook of emotion and memory: Research and theory (pp. 113-149). Hillsdale, NJ: Erlbaum

Rubin, D.C., \& Friendly, M. (1986). Predicting which words get recalled: Measures of free recall, availability, goodness, emotionality, and pronounceability for 925 nouns. Memory and Cognition, 14, 79-94.

Walker, E.L. (1958). Action decrement and its relation to learning. Psychological Review, 65, 129-142.

Walker, E.L., \& Tarte, R.D. (1963). Memory storage as a function of arousal and time with homogeneous and heterogeneous lists. Joumal of Verbal Leaming and Verbal Behavior, 2, 113-119.

Wessel, I., Van der Kooy, P., \& Merckelbach, H. (2000). Differential recall of central and peripheral details of emotional slides is not a stable phenomenon. Memory, 8, 95-109.

Received November 27, 2001

Revision received April 10, 2002 Accepted May 10, 2002 


\section{APPENDIX}

Words used as stimuli in Experiments 1, 2, and 3

Experiment 1

\begin{tabular}{ll}
\hline Neutral words & Emotional words \\
\hline Bolsillo [pocket] & Fruta [fruit] \\
Onda [wave] & Infancia [infancy] \\
Capa [cloak] & Lluvia [rain] \\
Párrafo [paragraph] & Paisaje [landscape] \\
Cálculo [calculation] & Regalo [present] \\
Guante [glove] & Clavel [carnation] \\
Firma [signature] & Pareja [couple] \\
Cimiento [foundations] & Excursión [excursion] \\
Perfil [profile] & Danza [dance] \\
Comercio [commerce] & Nieto [grandson] \\
Átomo [atom] & Burla [gibe] \\
Lámpara [lamp] & Examen [exam] \\
Década [decade] & Cadáver [corpse] \\
Hilo [thread] & Fascismo [fascism] \\
Media [stocking] & Fiebre [fever] \\
Carbón [coal] & Grasa [fat] \\
Signo [sign] & Mosca [fly] \\
Comarca [region] & Navaja [clasp knife] \\
Portada [cover] & Hospital [hospital] \\
Germen [germ] & Robo [theft] \\
\hline
\end{tabular}


Experiments 2 and 3

\begin{tabular}{|c|c|}
\hline Neutral words & Emotional words \\
\hline Anuncio [advertisement] & Nieto [grandson] \\
\hline Músculo [muscle] & Clavel [carnation] \\
\hline Congreso [congress] & Infancia [infancy] \\
\hline Rótulo [placard] & Danza [dance] \\
\hline Firma [signature] & Regalo [present] \\
\hline Hilo [thread] & Excursión [excursion] \\
\hline Mezcla [mixing] & Examen [exam] \\
\hline Programa [program] & Cadáver [corpse] \\
\hline Vitrina [glass case] & Robo [theft] \\
\hline Portada [cover] & Fascismo [Fascism] \\
\hline Dictado [dictation] & Fiebre [fever] \\
\hline Pestaña [eyelash] & Navaja [clasp knife] \\
\hline \multicolumn{2}{|l|}{ Oficial [official] } \\
\hline \multicolumn{2}{|l|}{ Receta [recipe] } \\
\hline \multicolumn{2}{|l|}{ Década [decade] } \\
\hline \multicolumn{2}{|l|}{ Germen [germ] } \\
\hline \multicolumn{2}{|l|}{ Rodilla [knee] } \\
\hline \multicolumn{2}{|l|}{ Carbón [coal] } \\
\hline \multicolumn{2}{|l|}{ Aviso [warning] } \\
\hline \multicolumn{2}{|l|}{ Comarca [region] } \\
\hline \multicolumn{2}{|l|}{ Media [stocking] } \\
\hline \multicolumn{2}{|l|}{ Transporte [transport] } \\
\hline \multicolumn{2}{|l|}{ Cimiento [foundations] } \\
\hline \multicolumn{2}{|l|}{ Cuesta [slope] } \\
\hline \multicolumn{2}{|l|}{ Signo [sign] } \\
\hline \multicolumn{2}{|l|}{ Guante [glove] } \\
\hline \multicolumn{2}{|l|}{ Cálculo [calculation] } \\
\hline \multicolumn{2}{|l|}{ Lámpara [lamp] } \\
\hline \multicolumn{2}{|l|}{ Átomo [atom] } \\
\hline \multicolumn{2}{|l|}{ Onda [wave] } \\
\hline \multicolumn{2}{|l|}{ Tejado [roof] } \\
\hline \multicolumn{2}{|l|}{ Perfil [profile] } \\
\hline \multicolumn{2}{|l|}{ Conercio [commerce] } \\
\hline \multicolumn{2}{|l|}{ Comedor [dining room] } \\
\hline \multicolumn{2}{|l|}{ Capa [cloak] } \\
\hline \multicolumn{2}{|l|}{ Bolsillo [pocket] } \\
\hline \multicolumn{2}{|l|}{ Trozo [bit] } \\
\hline Párrafo [paragraph] & \\
\hline
\end{tabular}

